\title{
OPEN Generalization of intrinsic ductile-to-brittle criteria by Pugh and Pettifor for materials with a cubic crystal structure
}

\author{
O. N. Senkov \& D. B. Miracle
}

Two classical criteria, by Pugh and Pettifor, have been widely used by metallurgists to predict whether a material will be brittle or ductile. A phenomenological correlation by Pugh between metal brittleness and its shear modulus to bulk modulus ratio was established more than 60 years ago. Nearly four decades later Pettifor conducted a quantum mechanical analysis of bond hybridization in a series of intermetallics and derived a separate ductility criterion based on the difference between two singlecrystal elastic constants, $\mathrm{C}_{12}-\mathrm{C}_{44}$. In this paper, we discover the link between these two criteria and show that they are identical for materials with cubic crystal structures.

Ductility is an essential property, it allows materials to be shaped into useful parts and to accept limited damage in service without failing. Brittle materials cannot be formed into components using conventional methods, and cannot be used as structural materials since failure can occur unexpectedly due to defects and stress concentrations. There are several well-known methods for strengthening materials along with physical models that can accurately predict strength. However, there are no general, physical models for predicting ductility ${ }^{1}$. Therefore, it is important for materials discovery and development to have rules that can predict if a selected composition will be brittle or ductile. In the early 1950's Pugh used empirical reasoning that linked the shear modulus, G, with ductility and the bulk modulus, B, with fracture. After analyzing experimental data from dozens of elemental metals, Pugh found that metals with a small ratio, G/B, were generally ductile, whereas metals with a high G/B ratio were generally brittle ${ }^{2}$. Pugh did not propose a critical $\mathrm{G} / \mathrm{B}$ value for the transition from ductile to brittle behavior; however, later analysis of a number of crystalline alloy systems suggested that brittle behavior would be common when $\mathrm{G} / \mathrm{B} \geq 0.57-0.6^{1,3-5}$, while in metallic glasses a sharp transition was observed at $\mathrm{G} / \mathrm{B} \approx 0.41-0.43^{6,7}$.

In the late 1980s and early 1990s Pettifor ${ }^{8,9}$ conducted a quantum mechanical analysis of bond hybridization in a series of intermetallics and derived a separate ductility criterion based on the difference between two singlecrystal elastic constants, $\mathrm{C}_{12}$ and $\mathrm{C}_{44}$. According to Pettifor's criterion, which was derived using a many body potential that explicitly includes the angular character of the bonding orbitals ${ }^{8,10}$, material with non-directional metallic bonds is intrinsically ductile and has a positive Cauchy pressure, $C^{\prime \prime}=C_{12}-C_{44}>0$; whereas material with negative Cauchy pressure $\left(C^{\prime \prime}<0\right)$ possesses directional, covalent bonding and is intrinsically brittle ${ }^{8,9}$. Since then, efforts to predict whether a material will be brittle or ductile have used one or the other of these two (Pugh or Pettifor) criteria.

Recently Niu et al. ${ }^{5}$ analyzed the properties of a number of ductile and brittle materials with cubic crystal structures. While previous efforts have generally used either $\mathrm{Pugh}^{2}$ or Pettifor ${ }^{8,9}$ criteria to identify the intrinsic ductile-to-brittle transition as a function of elastic properties, Niu et al. ${ }^{5}$ attempted to find a correlation between these criteria by analyzing 308 intermetallic compounds and 24 metals and semi-metals. When they plotted C" versus $\mathrm{G} / \mathrm{B}$, a very large scatter was found indicating poor correlation between these parameters (Fig. 1a). However, when C" was normalized by Young's modulus E (i.e. when the C"/E ratio was used), the materials followed a broadly hyperbolic trend (Fig. 1b). Unfortunately, an explanation of the origin of this intriguing correlation was not given.

In the present report, we derive a relationship between the Cauchy pressure and Pugh's modulus ratio and show that these two classical criteria are identical for materials with cubic crystal structures. 

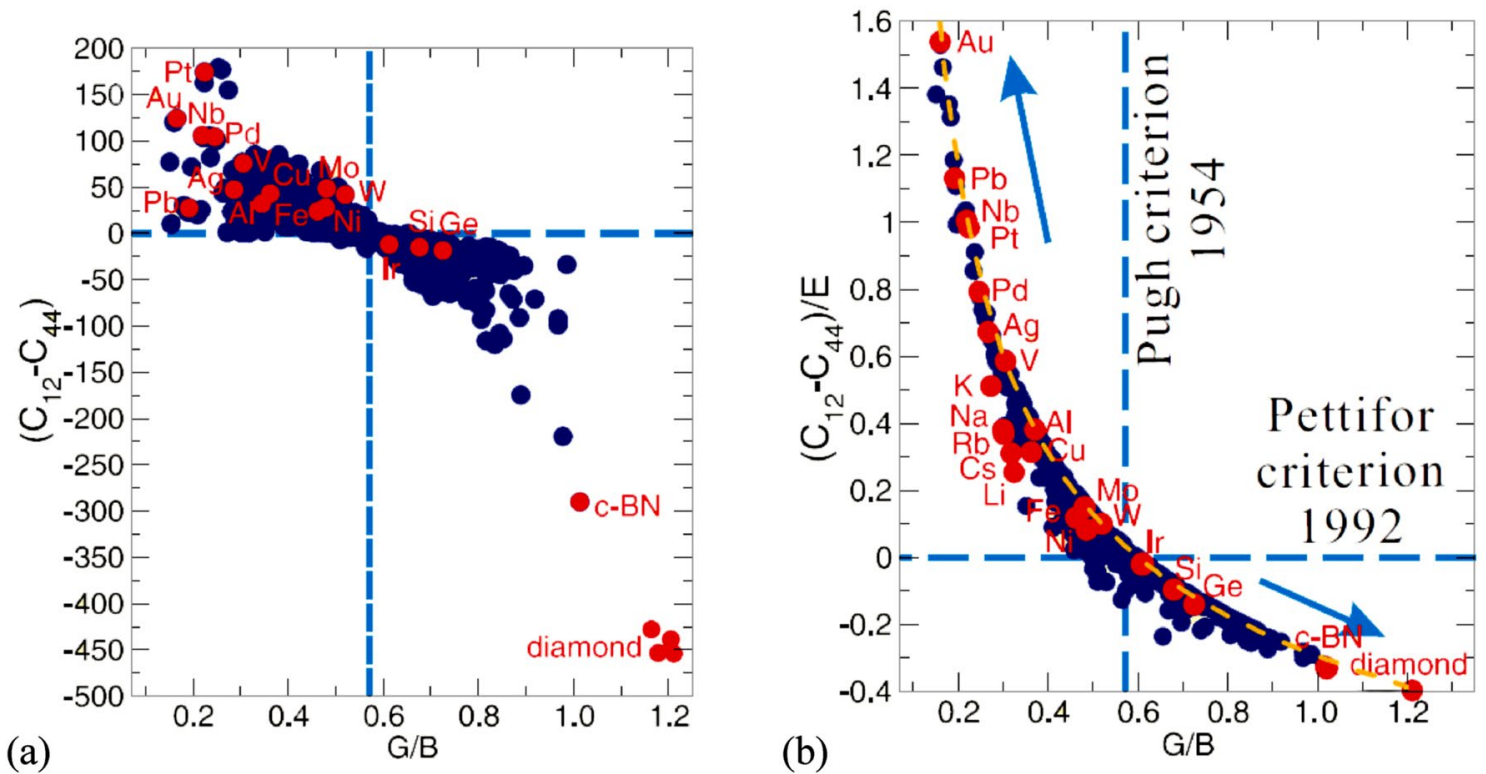

Figure 1. (a) Correlation between $C "=\left(C_{12}-C_{44}\right)$ and $G / B$ for 308 compounds and 24 metals given in Supplementary materials of ; (b) a renormalized hyperbolic correlation between $\mathrm{C}^{5}$ normalized by Young modulus $\mathrm{E}$ and $\mathrm{G} / \mathrm{B}$ for all the data from (a). The horizontal dashed line corresponds to $\mathrm{C}=0$ and the vertical dashed line corresponds to $\mathrm{G} / \mathrm{B}=0.57$. (Compiled from ${ }^{5}$.) A dashed yellow data trendline in $(\mathbf{b})$ corresponds to Eq. (8).

\section{Results and discussion}

For cubic crystals, the macroscopic Voigt shear modulus $\mathrm{G}_{\mathrm{v}}$ and bulk modulus $\mathrm{B}$ can be expressed as functions of the elastic constants $\mathrm{C}_{11}, \mathrm{C}_{12}$ and $\mathrm{C}_{44}{ }^{11,12}$ :

$$
\begin{gathered}
5 \mathrm{G}_{\mathrm{v}}=3 \mathrm{C}_{44}+\mathrm{C}_{11}-\mathrm{C}_{12} \\
3 \mathrm{~B}=\mathrm{C}_{11}+2 \mathrm{C}_{12}
\end{gathered}
$$

Combining these two equations and eliminating $\mathrm{C}_{11}$, one obtains

$$
C_{12}-C_{44}=B\left(1-\frac{5 G_{v}}{3 B}\right)
$$

From Eq. (3), Pettifor's condition for insipient brittleness, $\left(C_{12}-C_{44}\right)<0$, occurs when $G_{v} / B>0.6$. It is necessary to point out that the Voigt shear modulus represents the upper bound of the macroscopic shear modulus $\mathrm{G}$, which value is between Voigt and Reuss estimates and is often taken as an arithmetic average of these two values ${ }^{11}$. The Reuss shear modulus $\mathrm{G}_{\mathrm{r}}$ is the lower bound for $\mathrm{G}$ and is defined as

$$
G_{r}=\frac{5 C_{44}\left(C_{11}-C_{12}\right)}{4 C_{44}+3\left(C_{11}-C_{12}\right)}=\frac{C_{44}\left(5 G_{v}-3 C_{44}\right)}{3 G_{v}-C_{44}}
$$

while the Reuss bulk modulus $B_{r}$ is equal to Voigt bulk modulus $B_{v}$ and is given by Eq. (2), i.e. $B_{r}=B_{v}=B^{11}$. For isotropic cubic crystals, $\left(C_{11}-C_{12}\right) / 2=C_{44}$ and $G=G_{r}=G_{v}=C_{44}$. Therefore, Pettifor's condition for insipient brittleness of isotropic cubic crystals occurs when $\mathrm{G} / \mathrm{B}>0.6$.

For anisotropic cubic crystals, $\left(\mathrm{C}_{11}-\mathrm{C}_{12}\right) / 2 \neq \mathrm{C}_{44}, \mathrm{G}_{\mathrm{r}}<\mathrm{G}<\mathrm{G}_{\mathrm{v}}$, and the ductile-to-brittle transition occurs at a $G / B$ ratio smaller than 0.6 . Indeed, in this case $G_{r}$ and $G=\left(G_{v}+G_{r}\right) / 2$ can be expressed as functions of $G_{v}$ and the Zener anisotropy ratio $\mathrm{A}=\left(2 \mathrm{C}_{44}\right) /\left(\mathrm{C}_{11}-\mathrm{C}_{12}\right)$ :

$$
\begin{aligned}
G_{r} & =\frac{25 A}{(2+3 A)(3+2 A)} G_{v} \\
G & =\frac{3 A^{2}+19 A+3}{(2+3 A)(3+2 A)} G_{v}
\end{aligned}
$$

When $A=2, G_{r}=0.89 G_{v}, G=0.95 G_{v}$ and the ductile to brittle transition occurs at $G / B=0.57$. This $G / B$ value is typically used for the Pugh criterion ${ }^{5}$. For materials with $A=3$ (e.g. $\mathrm{Ag}, \mathrm{Au}$ and $\mathrm{Cu}$ all have $A \approx 3$ ), $\mathrm{G}_{\mathrm{r}}=0.76 \mathrm{G}_{\mathrm{v}}$ and $G=0.88 G_{v}$, and, according to Eq. (3), these materials are brittle if $G / B>0.53$. Our analysis thus gives physical meaning to the Pugh criterion. Indeed, for an isotropic cubic crystal, $G=G_{v}$ and Pettifor's condition for insipient brittleness, $\left(\mathrm{C}_{12}-\mathrm{C}_{44}\right)<0$, occurs when $\mathrm{G} / \mathrm{B}>(\mathrm{G} / \mathrm{B})_{\mathrm{dbt}}=0.6$. (The subscript 'dbt' indicates that the value 


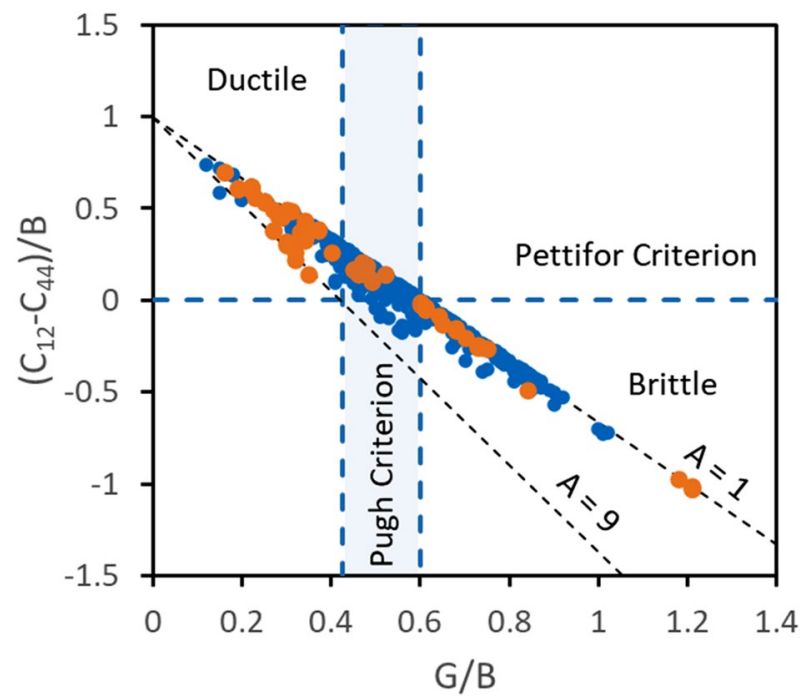

Figure 2. Correlation between $C " / B=\left(C_{12}-C_{44}\right) / B$ and $G / B$ for 308 compounds (blue points) and 24 metals (brown points) with cubic crystal structures analyzed in ${ }^{5}$. The linear trendlines are described by Eq. (6) for isotropic $(A=1)$ and highly anisotropic $(A=9)$ materials. The vertical band corresponds to $G / B$ in the range of 0.42 to 0.6 to account for the effect of elastic anisotropy on the value of $G$ at $C_{12}-C_{44}=0$.

corresponds to the ductile to brittle transition boundary.) Because these two conditions occur simultaneously, this indicates, that an increase in $\mathrm{G} / \mathrm{B}$ ratio above 0.6 should result in the formation of directional, covalent bonding and brittleness, in accord to Pettifor's theor ${ }^{8,9}$. Additionally, our analysis also shows that in anisotropic cubic crystals the transition from non-directional, metallic bonds to directional, covalent bonds occurs at a smaller $\mathrm{G} / \mathrm{B}$ ratio, as increasing A beyond unity decreases the critical G/B value.

Equations (3) and (5) indicate that a linear relationship between C"/B and G/B should be met, with a negative slope increasing with increasing A:

$$
\frac{C^{\prime \prime}}{B}=1-\frac{5(2 A+3)(2+3 A)}{3\left(3 A^{2}+19 A+3\right)} \frac{G}{B}
$$

Accordingly, Pettifor's brittleness condition C" $<0$ becomes equivalent to the Pugh condition when modified to account for elastic anisotropy:

$$
\frac{G}{B}<\frac{3\left(3 A^{2}+19 A+3\right)}{5(2 A+3)(2+3 A)}
$$

To verify this, we plotted the experimental data used by Niu et al. ${ }^{5}$ in the coordinates of C"/B versus G/B in Fig. 2. It is found that indeed the data follow a linear relationship between these two parameters. The spread of the data is due to different A values, which vary from 0.14 to 9 for the analyzed materials. To visualize the effect of elastic anisotropy, two trendlines (Eq. 6) are plotted, one for $A=1$ and another for $A=9$ (or $A=1 / 9$, as Eq. (6) provides equivalent solutions for $A=A^{\prime}$ and $\left.A=1 / A^{\prime}\right)$. It is seen that the dependence of $C^{\prime \prime} / B$ on $G / B$ becomes stronger and Pettifor's condition for incipient brittleness occurs at smaller G/B values with increasing elastic anisotropy. The Pettifor criterion gives a discrete boundary between intrinsically ductile and brittle materials at $\left(\mathrm{C}_{11}-\mathrm{C}_{12}\right) / \mathrm{B}=0$, but the present analysis shows that this translates to a range in $\mathrm{G} / \mathrm{B}$ to delineate brittle from ductile behavior (Eq. 7). For elastically isotropic materials this transition occurs at $(\mathrm{G} / \mathrm{B})_{\mathrm{dbt}}=0.6$, but the critical $\mathrm{G} / \mathrm{B}$ value decreases to $(\mathrm{G} / \mathrm{B})_{\mathrm{dbt}}=0.42$ with increasing the elastic anisotropy (see Fig. 2 ). This distributed boundary is fully consistent with Pugh's original analysis, where a specific value in G/B was not proposed ${ }^{2}$.

Our analysis also shows that the bulk modulus rather than Young's modulus should be used to normalize the Cauchy pressure and obtain the linear relationship between the bulk modulus reduced Cauchy pressure and shear modulus. On the other hand, considering that $E=\frac{9 B G}{3 B+G}$ and using Eq. (3) one can show that C"/E is a non-linear function of $\mathrm{G} / \mathrm{B}$ :

$$
\frac{C^{\prime \prime}}{E}=\frac{B}{9 G_{v}}\left(3+\frac{G_{v}}{B}\right)\left(1-\frac{5 G_{v}}{3 B}\right)
$$

This explains the "hyperbolical" correlation between C"/E and G/B previously found by Niu et al. ${ }^{5}$ (see yellow dashed line in Fig. 1b).

It is necessary to point out, that the above analysis was conducted for materials with cubic crystal structures and the results may not be applied to materials with non-cubic crystal structures. Reduced symmetry in non-cubic crystal structures requires expansion of the $\mathrm{C}_{\mathrm{ij}}$ matix to include terms beyond just $\mathrm{C}_{11}, \mathrm{C}_{12}$ and $\mathrm{C}_{44}$, dramatically complicating relationships between $\mathrm{C}_{\mathrm{ij}}$, $\mathrm{G}$ and $\mathrm{B}$. A universal elastic anisotropy index that includes 
non-cubic crystals, $\mathrm{A}^{\mathrm{U}}$, has been derived from variational principles of elasticity and consideration of the spheri$\mathrm{cal}$ and deviatoric components of the elastic constants ${ }^{13}$. While this opens the possibility of a universal ductility criterion based on elastic properties alone, quantifying $\mathrm{A}^{\mathrm{U}}$ requires knowledge of the fourth order deviatoric components of the elasticity tensor, making its general application impractical.

In conclusion, our analysis shows that two classical brittle-to-ductile transition criteria, Pugh's modulus ratio and Pettifor's Cauchy pressure, are equivalent for materials with cubic crystal structures and they should be considered as one, the Pugh-Pettifor criterion. We derive a new equation establishing the equality between these previous two criteria.

\section{Methods}

Analytical methods were used to derive the relationships, Eqs. (3) through (8). These relationships were verified using the experimental data from Ref. ${ }^{5}$.

Received: 11 December 2020; Accepted: 9 February 2021

Published online: 25 February 2021

\section{References}

1. Thompson, R. P. \& Clegg, W. J. Predicting whether a material is ductile or brittle. Curr. Opin. Solid State Mater. Sci. 22, 100-108. https://doi.org/10.1016/j.cossms.2018.04.001 (2018).

2. Pugh, S. F. X. C. I. I. Relations between the elastic moduli and the plastic properties of polycrystalline pure metals. Philos. Mag. 7(45), 823-843. https://doi.org/10.1080/14786440808520496 (1954).

3. Tabor, D. The Hardness of Metals (Oxford University Press, Oxford, 2000).

4. Gilman, J. J. Electronic Basis of the Strength of Materials 142-173 (Cambridge University Press, Cambridge, 2003).

5. Niu, H. et al. Extra-electron induced covalent strengthening and generalization of intrinsic ductile-to-brittle criterion. Sci. Rep. 2, 718. https://doi.org/10.1038/srep00718 (2012).

6. Lewandowski, J. J., Wang, W. H. \& Greer, A. L. Intrinsic plasticity or brittleness of metallic glasses. Philos. Mag. Lett. 85, 77-87. https://doi.org/10.1080/09500830500080474 (2005).

7. Narasimhan, R., Tandaiya, P., Singh, I., Narayan, R. L. \& Ramamurty, U. Fracture in metallic glasses. Int. J. Fracture 191, 53-75. https://doi.org/10.1007/s10704-015-9995-3 (2015).

8. Pettifor, D. G. \& Aoki, M. Bonding and structure of intermetallics: A new bond order potential. Phil. Trans. R. Soc. Lond. 334, 439-449 (1991).

9. Pettifor, D. G. Theoretical predictions of structure and related properties of intermetallics. Mater. Sci. Technol. 8, 345-349 (1992).

10. Pettifor, D. G. New many-body potential for the bond order. Phys. Rev. Lett. 63, 2480-2483. https://doi.org/10.1103/PhysRevLett. 63.2480 (1989).

11. Hill, R. The elastic behaviour of a crystalline aggregate. Proc. Phys. Soc. A 65, 349-354 (1952).

12. Jamal, M., Asadabadi, S. J., Ahmad, I. \& Aliabad, H. A. R. Elastic constants of cubic crystals. Comp. Mater. Sci. 95, 592-599. https:// doi.org/10.1016/j.commatsci.2014.08.027 (2014).

13. Ranganathan, S. I. \& Ostoja-Starzewski, M. Universal elastic anisotropy index. Phys. Rev. Lett. 101, 055504. https://doi.org/10. 1103/PhysRevLett.101.055504 (2008).

\section{Acknowledgements}

Discussions with Dr. Satish Rao are appreciated. Financial support through the Air Force Research Laboratory core funding is acknowledged. Work by ONS was also supported through the Air Force on-site contract FA865015-D-5230 managed by UES, Inc., Dayton, Ohio.

\section{Author contributions}

O.N. Senkov conducted the analysis and wrote the manuscript. D.B. Miracle contributed to the discussion and writing the manuscript.

\section{Competing interests}

The authors declare no competing interests.

\section{Additional information}

Correspondence and requests for materials should be addressed to O.N.S.

Reprints and permissions information is available at www.nature.com/reprints.

Publisher's note Springer Nature remains neutral with regard to jurisdictional claims in published maps and institutional affiliations.

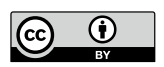

Open Access This article is licensed under a Creative Commons Attribution 4.0 International License, which permits use, sharing, adaptation, distribution and reproduction in any medium or format, as long as you give appropriate credit to the original author(s) and the source, provide a link to the Creative Commons licence, and indicate if changes were made. The images or other third party material in this article are included in the article's Creative Commons licence, unless indicated otherwise in a credit line to the material. If material is not included in the article's Creative Commons licence and your intended use is not permitted by statutory regulation or exceeds the permitted use, you will need to obtain permission directly from the copyright holder. To view a copy of this licence, visit http://creativecommons.org/licenses/by/4.0/.

This is a U.S. Government work and not under copyright protection in the US; foreign copyright protection may apply 2021 